\title{
STS in Management Education: Connecting Theory and Practice
}

\begin{abstract}
This paper explores the value of science and technology studies (STS) to management education. The work draws on an ethnographic study of second year management undergraduates studying decision making. The nature and delivery of the decision making module is outlined and the value of STS is demonstrated in terms of both teaching method and module content. Three particular STS contributions are identified and described: the social construction of technological systems; actor network theory; and ontological politics. Affordances and sensibilities are identified for each contribution and a discussion is developed that illustrates how these versions of STS are put to use in management education. It is concluded that STS has a pivotal role to play in critical management (education) and in the process offers opportunities for new forms of managing. Key words. ontological politics; ethnography; management education; actor network theory; STS
\end{abstract}

\section{Introduction}

This paper explores the value of science and technology studies (STS) to management education. In pursuing this, we draw on ethnographic fieldwork undertaken in a UK business school. The ethnography involved work with second year management undergraduates studying a module in management decision making: "MGT2005". This unit is single semester in length and involves students in an extended problembased learning exercise (PBL). In this introduction, we briefly locate our work within the broad tradition of critical management studies (CMS). We then outline the nature and delivery of the decision making module and in the process identify value in STS in terms of both our teaching method and module content. Attention then turns to consideration of those aspects of STS that we have selected, and the particular STS examples and voices that we invoke. In this context, we outline and discuss the affordances and sensibilities that our particular versions of STS carry. Finally, we conclude that in combining problem-based learning, STS theory and ethnographic field practices, we have identified an opportunity for STS to become involved in management (education).

CMS represents a diverse and concerted challenge to management orthodoxy by directly challenging universal reductions of management to concerns for technical competency and instrumental rationality (Roberts, 1996). Notwithstanding particular theoretical commitments, CMS critiques of management have established the relevance of social processes for management. We locate our own work here within the broad tradition of post-structural approaches to CMS. In this context, for over two decades, there has been considerable academic effort in deconstructing managerial theory and practice. Inevitably, epistemology is central to this post-structural effort where management is examined as a constructed category ${ }^{1}$. 
During the 1990s, whilst CMS is foregrounding epistemology and problematising the constructed nature of management, we also find, in the UK, a significant expansion in management education: business enters the academy. Inevitably, given CMS interest in knowledge production processes, management education is identified as a significant site where management is constructed and reproduced. Consequently, the attendant growth of management consultancy, curricula and pedagogic practices in higher education requires scrutiny (see Parker, 2002; Grey, 2002). Indeed, in 1996 French and Grey edited a seminal collection entitled, Rethinking Management Education, that mapped the terrain of CMS and education. In this text the contributors argued for changing pedagogic practices in management education. The point of concern throughout was that management education tended toward a rationalist/training agenda that treated management knowledge as a commodity and the production of such knowledge as unproblematic. In critiquing this situation, French and Grey illustrated the need to consider management education as a process and sought to challenge the very notion of management effectiveness with its normative commitments to managerialism. The debate that French and Grey began is still lively, open and current (see Fulop, 2002; Zald, 2002) and we seek here to introduce STS into the mix.

For almost four decades there has been considerable research interest in science. This interest has been multidisciplinary and has focused attention upon scientific knowledge production and science practices ${ }^{2}$. Each contributing discipline has provided seminal insights into science. Notwithstanding fierce disagreement on certain points of theory/method, their classic studies have produced a tacit understanding of science as social practice. Alongside this interest in science there has been an associated interest in applied science and technology. Again, the research effort here has been multidisciplinary and the theoretical and empirical work productive. This broad area of interest incorporates both science and technology studies (STS). To develop our discussion and provide a background to how we work with STS in management education - our ethnography - we now firstly outline 'where' and 'how' STS is situated in our pedagogy before moving on to pay closer attention to our selected versions of STS.

\section{STS meets MGT2005 Decision Making: Theory and Practice}

STS appears in our management education in two specific ways. Firstly, STS informs the manner in which we conduct our teaching and learning. Secondly, we rely solely on STS for our theoretical and empirical content ${ }^{3}$. In order to examine our two appropriations of STS, we discuss the particularities of STS in our daily educational practice before turning attention to the selection and role of theory. However, we begin first with some practical background to the module that is at the heart of our ethnography.

Decision Making: theory and practice is a single semester module of study on the second year of an undergraduate award in management. Typically, the module is known by its unique identifier MGT2005. Four learning outcomes frame the module and each learning outcome reflects an aspect of the CMS imperative to problematise managerialism in theory and practice ${ }^{4}$. MGT2005 is well documented and, in week one, each student receives a guide that outlines the programme of study, the teaching and learning approach, reading lists and assessment.
Comment [CC1]: Please review use of present and past tense.

Comment [CC2]: The purpose of this
paragraph is not really clear until the end.
Is there a way of reworking this that
makes it fit better into the flow of the
text? Also, as a summary statement of
what STS 'is' it seems a bit vague (e.g.
you mention multiple disciplines rather
than saying what these disciplines are).
Can this be remedied?

Comment [CC2]: The purpose of this Is there a way of reworking this that makes it fit better into the flow of the xt? Also, as a summary statement of you mention mulliple disciplines rather Can this be remedied? 
The teaching and learning approach focuses on problem-based learning (PBL). An imperative of PBL is that students inquire into issues and concerns that emerge both from formal teaching and their activities. In developing our PBL we construct an assignment around a significant problem. Investigating and addressing this problem will occupy students for the entire semester. The problem gives a sense of pace and urgency to the module and requires that students begin to organise immediately. In the academic year 2005/06, the concern was to investigate means to draw students deeper into the academic community of the business school and in the process to raise and confront any latent commodification of either their studies or themselves (Grey, Knights and Willmott, 1996:103).

In addition to the problem statement the assignment identifies four elements of assessment: a tender (bidding for a budget of $£ 500$, submitted in week 5); an individual reflective log (submitted week 7); a course "event” (week 10) and finally, an end of module individual viva (undertaken in week 14). Our assessment regime reflects our particular brand of PBL in that it places considerable value on reflection.

The assessment for the module has two moments where students are required to fold theory back onto their own practice in order to comment on both theory and practice. As a practical point, we recommend that students maintain a journal or scrapbook that can act as a record of mundane actions and experiences. This document may be solely text or may be supplemented with objects, photographs or any other matter that students think relevant. For us this record serves as a useful point of discussion in tutorials whilst for students, it is a valuable aid when they reflect on and with theory.

\section{Tutorial and Seminar Support: Connecting STS Ethnographic Performances and MGT2005}

Both seminars and informal tutorials play a major role in our STS brand of management education. As we shall show, we are often asking students to handle difficult theoretical concepts and to think with these concepts in particularly difficult circumstances. Seminars and tutorials become the educational opportunities for us to clarify, explain, challenge and affirm student work. However, the formal spaces and places in which tutorials and seminars occur are heavily inscribed. Our offices and seminar room do not simply offer a backcloth to the situated performances of tutorials. Rather, the furniture, lighting, shape and size of the room co-produce tutorials [refs]. The expected performances are well understood by both student and staff and we have all rehearsed them a great deal.

In tutorial performances we show how STS has value. We seek to change the inscribed relationships that circulate in the clinical rooms we normally inhabit. To do so we refurnish or simply change location and situation. Indeed, something as simple as meeting in coffee bars, internal public spaces or external 'comfort' spots on campus can have a profound effect. Whilst changing location is essential to our demonstration, we also draw directly on STS fieldwork practice in rethinking tutorials. In particular, we draw experiences of fieldwork into rethink our performances of tutor. By temporarily turning teaching into fieldwork, we allow notions from fieldwork to enter into our vocabulary and extend our interests to fieldwork relationships, rapport and politics of our practice.

Many seminal STS works have been developed around deep field ethnographies ${ }^{5}$. These ethnographies are anthropological in nature and draw researchers into complex relationships over extended periods of time. Equally, studies that involve and develop 
anthropological sensibilities are also subject to the methodological concerns that circulate around deep ethnography. In this context, the well theorised anthropological concerns over rapport and politics of practice become STS concerns as notions of collaboration, complicity and friendship are drawn into examinations of fieldwork practice (see Marcus, 1997; Rabinow, 1997; Clifford, 1997 and Strathern ed, 1995). It is clear that whether working with laboratory scientists, radiologists or hill farmers, STS research often demands attention to relationships between researcher and researched. In these situations our fieldwork collaborators invite us into part of their lives: we eat, share jokes, make friends, smile and worry as we 'study'. Latour's evocative study of a field trip to the Amazonian Boa Vista connects theory, fieldwork and relationships in graphic ways (Latour, 1995) [in what way].

In teaching, we initially focus our tutorial practice on collaboration and in effect we act as co-travellers with the students as they problem solve and co-producers of whatever they make MGT2005 to be. Our role is to bring STS into the spaces and places of their decision making and engage the students in conversations over, about and with STS in decision making. In thinking through tutorials, we draw on experiences from fieldwork and reflect that, at appropriate moments in fieldwork, we often share our translation (transcription) [where does this come from?] of immediate events with the locals and engage in extended conversations or even debates over different political cuts and takes that those involved are performing around a particular thing or event ${ }^{6}$. This conversational form of interaction is central to fieldwork and allows all sides to explain and review the meaning and interpretations that they are producing and co-producing. At times, fieldwork analysis is a (co) production of these conversations and experiences. However, at other times, we draw a line across these interactions and reassert our own particular responsibilities as (sociological) tutor/analysts. At such time we fall back on the basic test for ethnographic accounts - that is, even if our (friends) (collaborators) conspirators have not been involved in co-producing the point or interpretation, they must at least recognise the description and the account of themselves in our re-telling.

In developing our tutorial practices we draw on fieldwork to rethink the quality and power relations that are extant in performances of student/tutor. We absolutely refuse to be positioned as 'expert'. Nor do we play games with students, where there is a set of clues that must be followed and performances that must be done. We are not holding back the next clue as they struggle to make sense of the uncertainties they meet in problem solving. Rather, our approach is conversational and complicit. Our only provision is that, and this is the crucial educational aspect of our appropriation of fieldwork practices in teaching, we hold to our responsibilities as representatives of STS in the experiences of students. At times the STS voice is clear and demanding in our conversations, whilst at other moments, it is a far softer and encouraging voice.

\section{STS Voices in Management Education: the Case of MGT2005}

We have outlined above the basic foundations of the approach that we take in our MGT2005 and in the process we have indicated how STS sensibilities and fieldwork practices have allowed us to rethink our practice as educators. In this context, we have drawn attention to the significance of rapport and collaboration in our version of STS informed management education. We now turn to theory, and the selection and role of STS literature in our programme. 
In teaching MGT2005 we focus attention on the material performances that circulate in and around problem solving. Consequently, we draw on theory that addresses material performances: that is theory where materials matter (Barad, 2003). Our selected material is drawn from three sources: i) social construction of technological systems (SCOT), ii) actor network theory (ANT) and iii) ontological politics (OP). Each of these sources is rich in content and material, so we focus down again on three well developed examples: bicycles; walls and anaemia.

Our selection from the STS literature provides three different ways to investigate and sense materiality. Each approach wields particular terms, theoretical constructs and arguments. Before we turn attention to the detail and value of each of our selected examples, it is worth briefly commenting on our selection. In particular we wish to explain why we opt to use STS studies rather that the increasing body of STS informed organizational studies. Firstly, whilst there is quite a lot of emerging material in organization studies that draws on ANT [such as?] there is little literature that draws directly on SCOT or OP. Moreover, we have selected literature where theory is laid out with care and where the empirical illustrations are vivid: bicycle, wall, anaemia are all knowable even if not overtly managerial.

Whilst the STS literature that we use reveals theory in careful and artful ways, we have found a hidden bonus in drawing on STS literature: it is unsettling. We lecture on bikes, walls, anaemia and related things from weeks two through to week seven and this initially throws our students out of a comfort zone. When they first arrive at MGT2005, our selection of content seems at odds with their expectations. The exotic character of the material is puzzling and students spend time pondering the relevance of the material. It is this period of puzzling about the material that we find useful - it allows us to draw students into conversation and in these conversations we can draw on other technologies, their technologies, as a focus of attention.

Our intention is that over time we can help students to begin to see, feel and experience managerial work through new terms. It is a combination of experience, theory and reflection that comes together to offer new ways of knowing management. In this context, we are looking to give students toolsets. For example, they are able to deconstruct an excel budgetary model in terms of what is present and absent, and to recognise in their deconstructions the work that excel does and the durability that excel carries.

So far, so good. We have outlined the module under consideration and explained how STS both informs our educational practice and identified the three main STS voices that students encounter in MGT2005. We now turn attention to these STS voices. We draw on particular empirical examples so as to illustrate how these examples are made meaningful to management decision making.

\section{Pinch/Bijker and SCOT: Interpretative Flexibility and Closure}

As we have already suggested, STS has both a history and varied working practices. The first STS voice that we use in our management education is the combined voices of Trevor Pinch and Wiebe Bijker circa the mid 1980s. In selecting this period and Pinch/Bijker, we deliberately connect our management students with a particular moment in the history of STS, the point when a new direction was being mooted in the history and sociology of technology: that is a focus on the Social Construction of Technological Systems (SCOT). In particular, as insights into knowledge production processes in science were gathering into a coherent, formal and forceful critique of 
scientific rationalism, SCOT sought to draw these frames of reference and concerns into a rigorous examination of technological artefacts and the knowledge processes that circulated around them ${ }^{7}$.

Whilst many different approaches and concerns can be subsumed under the SCOT umbrella, in working with management students studying decision making, we have selected a specific literature and use it in particular ways. The literature that we use to represent SCOT is Trevor Pinch and Wiebe Bijker's account of social construction of bicycles (Pinch and Bijker, 1987) together with the seminal collected work edited by Bijker, Hughes and Pinch (1987), Pinch and Trocco's (2002) ethnography of The Moog synthesiser and Oudshoorn and Pinch's (2003) discussion of co-production of technologies. Although this is a substantial literature, we use it differentially. The main thrust of our work on SCOT revolves around Pinch/Bijker and their deconstruction of bicycles. Our primary concern is to raise notions of materiality, interpretative flexibility and closure. Pinch/Bijker place bicycles at the centre of their deconstruction of done things. The focus on a mundane technology produces a deconstruction of practice and agency that feels both concrete and empirical. Consequently, this piece is accessible to students as an introduction to materiality.

In articulating the social processes of technology, Pinch/Bijker draw on historical sources to illustrate how multiple possibilities, problems and social groups were associated with the emerging technology that is now recognisable as a bicycle. The discussion illustrates how 'bicycleness' became stabilised as problems were identified/lost, solutions deemed plausible/implausible and social groups deemed legitimate/illegitimate. For example, Pinch/Bijker point to the processes around which, in the 1890s, the 'air tyre' (now pneumatic tyre) came to be fixed as the bicycle tyre. The closing in place of the air tyre emerged through controversy, with protagonists arguing between the new air tyre and the existing solid version. At this point it could be argued that whilst different groups were still 'designing' bicycle, there was a degree of openness as to what a bicycle might be and how it may be constructed: there remained some flexibility in the interpretation of bicycle and things bike. Pinch/Bijker illustrate that engineers involved in designing artefacts were concerned with the level of vibration experienced by cyclists using "small wheeled vehicles" and for some engineers the air tyre was seen as a technical solution to this problem.

In deconstructing the air tyre debate, Pinch/Bijker demonstrate how the social groups involved around bicycles were experiencing different problems, imagining and experimenting with different solutions and in so doing aligning, competing, and contesting with one another. In unravelling this example, Pinch/Bijker illustrate how failure of a particular cherished solution or loss of a particular form of bicycle can be understood as a social phenomenon rather than a technological one. Air tyres become the 'fixed' form of bicycle tyre not because they are technically superior solutions to the problem of vibration but because the social forces around them became stronger once speed became the issue (Pinch and Bijker, 1987: 40-46).

The value here of introducing SCOT literature into management decision making theory is that SCOT allows us to examine taken-for-granted everyday materials and explore these materials as physical expressions of political intent. Importantly, in SCOT, attention is placed not only on the social milieu in which artefacts are constructed and used but also on the actual content of technology. By making management decision making theory the domain of SCOT, and drawing Pinch/Bijker 
into our studies, the management world can be rendered physical, tactile, material and made. A space is now available to juxtapose bikes with management technologies such as excel spreadsheets for budgetary control. Juxtaposition now becomes a powerful tool in management education where the materials of management become candidates for deconstruction and apparently closed mundane management materials lose some of their apparent naturalness. Students, working with new theoretical constructs such as interpretative flexibility and closure, reflect on their own experiences and practices and in so doing, make these constructs relevant to management decision making.

\section{Actor Network Theory: Organising Walls and Hybrid Material Performances}

In turning to actor network theory (ANT), we aim to help students focus on material performances and relationships that are part and parcel of social (managerial) life. ANT is a massive field and we must be careful here. Rather than risk our students being overpowered by various points of concern that circulate around theorising network, we attend to some basics and highlight a study in which some of the pivotal concepts were clearly articulated. Our selection directs attention to the power of materials in durable management practice. Our extending reading list (Latour, 1991; Law and Mol, 1994; Bijker and Law eds, 1992; Law, 1999; Law and Moser, 1999; Law, 2002) is designed to take students well beyond the points addressed in our core text. However, our interest in walls remains the major focus and defines our base-line requirement: that students examine management as relating material performances involving humans and non-humans in combined effort - net work.

The core text we have chosen to stand for ANT is accessible and offers a potent account of mundane technology: that is walls and their partners, doors and hinges (Latour, 1992). Latour commences his discussion by suggesting that contemporary sociological accounts of social life are missing something from their explanations: these are the 'social links sturdy enough to tie us all together' (1992:227). The missing something that Latour theorises is hard working, 'strongly social and highly moral' (1992:227). For Latour, the missing something are non-human. The imperative now is to draw non-humans and the work they perform visibly into our accounts of order, discipline, morality and control. To demonstrate his claim, Latour draws attention to what happens when a mundane technology fails, in his case when a door fails. He argues that such failures bring forth disorder and the disciplinary power delegated to the artefact is revealed.

In examining the failure of the door Latour begins to unravel relationships and performances that circulate around doors. The first step involves examining doors in their relationships to walls. Walls become a new point of interest. Latour describes how, when drawn into social life, walls both order space and discipline users and uses of space. In this context, walls are shown to be powerful actors in social life. Humans and non-human combine in hybrid relationships to organise space, and in the process define each other.

Latour examines such human-non-human hybrids in terms of (net) work. Drawing again on walls, he observes the huge human effort that would be required if managing space was performed as a wholly human enactment. Once walls are enrolled into managing then particular orderings of space become stable and durable. At this point, Latour extends the network by noting that if walls are to be effective they require a means of passage - otherwise the wall has to be destroyed if we need to cross the 
spatial boundary: walls need holes. If human-wall hybrids discipline space, then simply putting a hole in the wall will breach that discipline. Now, attention must turn to the (net) work required to manage human-wall-wall-holes. If this hybrid is to bring order it must manage nature and human interventions. It is possible that this new problem can be addressed by putting someone to work in order to watch over the hole. However, nature can still cross the boundary unimpeded and, as Latour points out later, disciplining human guardians can be a difficult affaire. Yet, wall-holes cannot be left unmanaged. If guards are risky, doors are more robust. Doors can be enrolled in the human-wall-hole hybrid to bring order and extend the disciplinary power of the hybrid over space.

The extension and unravelling of hybrids develop as Latour creates twists and turns around different types of hinges and the skilled use of doors. Latour illustrates how doors and hinges perform order and in the process he describes how power has been delegated to these hybrids as they are drawn into (or enrolled) in organising. In pursuing this simple account of wall-door-human hybridity, Latour demonstrates some of the basic tenets of ANT: non-human agency, material hybridity; delegation; performativity; enrolment and translation.

As attention moves from bicycles to walls, the students are captivated (and occasionally irritated) as they begin to see enrolments and delegations everywhere. As with SCOT, we use juxtaposition as a conversational device in teaching. Placing 'walls' and 'timetables' side by side allows us to turn attention to material performances of organising in the university. The effort that would be required to manage their university world becomes visible and its material, durable and relational character becomes the point of (seemingly) endless conversations. We make it clear to students that we have only begun to investigate the rich domain of ANT, and only touched on theoretical constructs. For some students ANT becomes an issue - a topic to pursue into third year and beyond. For others, walls are enough to unsettle and disrupt their view of mundane managerial technologies. Irrespective of whether walls is a stopping or starting point, we know from reflective logs, viva voce and personal correspondence that something important has been added to their own decision making mix.

\section{Ontological Politics: Multiples, Situations and Performances}

We now turn attention to our third and final STS voice, Mol's notion of ontological politics: anaemia. If bicycles offer us a sense of a firm and socially constructed reality and walls evoke a sense of material hybrid performances, anaemia introduces a philosophical turn. Mol's analysis is organised around the concept of ontological politics that shifts attention away from epistemological to ontological concerns. For $\mathrm{Mol}$, reality is not something singular and external to social action. Rather realities are multiple and performed in socio-material practices. The shift from epistemology to ontology that Mol introduces is important and our literature is selected with a view to clarifying this shift for our management students. In our teaching, we use Mol's paper on anaemia (Mol, 1999) as our core document to set out her contribution to the debates in extending and reopening actor network theory. Mol draws on fieldwork to focus attention on situated performances to demonstrate how reality is made in particular practices and circumstances. Our discussion now draws on her deliberate account of performances of anaemia.

Mol begins her account of performances of anaemia by examining three medical situations in which anaemia can be found. The first situation is when anaemia 
appears in a clinical setting such as when a patient presents themselves at a doctor's surgery with a problem and anaemia appears in the performances of diagnosis and treatment. In such a setting, diagnosis may involve a range of question and answers and a physical examination appropriate to the conditions. The second medical situation of anaemia that Mol identifies is the statistical form. This is a quite different situation and involves very different materials and practices. The statistical situation is laboratory based and the patient is present as a sample of blood and a case with particular attributes. The focus here is on haemoglobin levels in the blood. The practices involve testing and checking blood samples and relating the results to population norms. The final situation is pathophysiological. In this situation anaemia is both biological and individualized. This performance attempts to identify, for individuals, the level of blood haemoglobin required for effective transportation of oxygen through their body. In this performance the body is present as an individual environment with particular behaviours. The outcome of the tests here is to find the unique level of blood haemoglobin that marks the distinction between normal and abnormal in an individual.

Mol notes that in medical texts these three performances are taken as aspects of a single condition. Indeed, each performance may be seen as a related expert perspective on a single problem - anaemia. Mol points out that this sense of a unified object viewed from different perspectives is problematic. Indeed, at times these perspectives appear to contradict each other. For example, some patients will not present symptoms of clinical anaemia but will have a 'statistically deviant' haemoglobin level. In other words, in one medical situation they are anaemic whilst in another situation, they are not. In furthering the discussion, Mol moves to consider how these different medical situations coexist and how they connect with other medical and non-medical phenomenon.

In pointing to the issue of how sometimes contradictory locations coexist, Mol observes that this is often unproblematic - that a patient has certain signs and not others is understood and incorporated into the performance of medicine. However, the issue becomes more significant if we ask how the decision making around the detection of anaemia is conducted. Historically, in the UK, screening is not undertaken for anaemia and the clinical approach, where patients seek help because of symptoms, is deemed satisfactory. Mol ponders on where and how this decision was made - concluding that history was probably the most likely answer. She notes that in some cases the state has taken control. For example, in the UK, water is regulated, contagious diseases are controlled through immunization programmes and in some cases, national screening is carried out for breast and cervical cancer in women.

Mol points out that whatever the acknowledged reason for the decision that 'detection of anaemia is a clinical practice', fixing that fact in place will have involved a displacement or translation of the decision. For example, both screening and clinical practices may be translated into NHS budgets, clinical risk factors, technical feasibility and so forth. Thus for Mol, the crucial determinant of decision making is in the way that reality always has to be translated and displaced. So it is in these processes that politics is practiced, moral judgments are made and options get whittled down and fixed in place.

Mol develops her account to consider how realities relate and interfere with each other. She demonstrates that realties are never discrete and that they are always open to being drawn away or into other practices and other concerns. It is in this messy 
connecting linkage of realities that Mol finds the difficult problem: how decisions are made when potential interferences and options abound.

Mol's discussion not only extends the concerns of SCOT and ANT, it also requires we modify our favourite device - juxtaposition. Our new performance of juxtaposition requires far more reflection than the previous show, tell and ask. Mol reveals multiple interfering performances and students tend to unravel this contribution by back-tracking through their own experiences. For example, in MGT2005, the students became fascinated when they found that decision about their 'event' moved around a whole host of other university realities. Finance officers, space managers, and senior managers concerned with intellectual property associated with the use of the university logo, carried their material performances into decision making about the event. Eventually, decision making stabilised around matters of health and safety. In reflecting on decisions and how they stabilised, students could now explore how different realities of 'event' interfered, happily co-existed and at times, overwhelmed other realities.

\section{Putting STS to Work in Management Education}

The decision making course is fast paced. In week one students begin to organise themselves into work groups and work on their assignment task. In week two, Trevor Pinch and Wiebe Bijker (virtually) enter the proceedings in the form of a lecture and directed reading. So, from week two onward, decision making involves the social construction of bicycles. It seems unfair to expect students to drop straight into SCOT whilst studying decision making, and in those early weeks we seek out students and arrange to meet for small informal tutorials in coffee bars around campus. This addition of coffee bar spaces to the prescribed lecture and seminar locations is important for many reasons. For example, it provides a relatively relaxed location in which to build working relationships with students such that they feel adequately supported and able to approach us in a variety of settings. The early move to the coffee bar is also important in that it can become a valuable point of departure for reflection and we can refer back to these meetings when we explore the materiality of workspaces and how different material locations of work lead to different performances. These reflections serve not only to illustrate materiality but to affect their (managerial) performances. Finally, the coffee bar meetings allow us to do the more obvious work of tutorials, namely following up on how students are making sense of the course material and identifying any common problems or difficulties (XXXX, forthcoming).

Students respond well to the informal tutorial support that focuses on clarification and encouragement. Our first vignette is taken from one of these meetings and, as we have already suggested, the drama here is in not only what is said or done at this moment but also on how this moment features on student recollections of 'key moments ${ }^{8}$. We draw on a short extract from fieldwork with our student-decision makers to see how Pinch/Bijker are going down in week two of MGT2005: ${ }^{9}$

(Atrium coffee area. 4.30 ish. A re-arranged tutorial. We are seated with four students, a wad of coloured paper and some pens. Trevor Pinch is the centre of attention - or at least a diagram from his discussion of bikes]

$$
\begin{gathered}
\text { Jon: Right, now have we got this right then. Is Pinch is saying that all these } \\
\text { stakeholders know what a bike is and they argue it out? }
\end{gathered}
$$

Comment [CC3]: the reference to the student "event" needs some elaboration: what is this? It is only mentioned previously (p3 para 2) as part a list of student activities. 
$\{\mathrm{LH}$ interested in the translation from interpretative flexibility and closure to

stakeholders - goes for a gentle redirect\}

LH: OK Jon, let's have a look shall we. Really pleased you have read the text - and really really pleased you brought it with you... now (looking round the group) before we have a look at the bikes can you remember Trevor Pinch talking about interpretative flexibility (some nods some shaking of heads) - Ok, can we just have a look at that and see where it takes us - it's important...anyone got a take on...

Lucy: (hesitantly)...well / read that bit and / think / got it, is it when, well, this sounds daft but like before a bike has become a bike and lots of different opinions are floating around but a bike could still be like lots of...

Jon: yeah, one wheel, three wheels, small wheels, big and little wheels - yeah they hadn't got it right yet and

LH: (moving forward quietly interrupts) ok, I'm just going to stop you at that point guys,, you are definitely on your way but we need to go a bit slower and take a closer look. Now Jon, you just said they hadn't got it right yet... how does 'right' get made according to Pinch

Lucy: (emphatically) socially.

LH: (smiling) good - but what does that actually mean, look here (pointing to a diagram in the directed reading) - talk me through it ...

(Jon and Lucy hesitantly take turns walking through the diagram. The tutorial continues with questions on both side. Tutors offering affirmation whilst blocking false trails and over quick simplifications of the notions. The students begin to dig down into the ideas and realise there are some big notions tucked away in this discussion of bikes)

WM: so, can we lose the words stakeholder and focus on Pinch's concepts "interpretative flexibility" and "closure" - now, these are the two key concepts to get hold of and work out what exactly Pinch means. You ok on that?

Jon and Lucy: yeah - we've got a group meeting tonight - can we email you?

LH: yeah - but focus on getting at what Pinch means with those particular words... they are really important and we'll regroup on this in the lecture

In the above extract we are beginning, very gently, to surface and question some of the notions that the students are bringing to their studies. As we have already indicated, we have selected this extract because it features powerfully in both students' reflective logs and in the end of module viva. In explaining here why this was an important moment requires that we firstly focus on the specific encounter before moving offstage and pursue 'what happened next'.

In the above vignette, a tug-of-war is being played out between a reading that reduces and translates the Pinch/Bijker analysis of interpretative flexibility and closure involving relevant social groups into a more general discussion of stakeholders. Initially, we respond by gently pulling Jon back from his cherished word (stakeholder) and focusing attention on a more careful reading of the text. Even so, 
stakeholders keep popping up as students explain the diagrams to one another and investigate the argument. A hidden drama emerges as we continue to insist on close attention to theoretical vocabulary. Students have to work out why Pinch/Bijker prefer the cumbersome phrase invoking 'deep understanding' of "relevant social groups" over the more familiar term stakeholder. It can come as a shock to students when they realise that it is they who are concerned with stakeholders, not Pinch/Bijker. As we unravel this sociological moment, the students are often unaware of how or why they have selected this term. Over the next few days/weeks of inquiry we return to this moment and ask why. Why did stakeholders appear? How is 'stakeholders' done? and, why is stakeholder inadequate for Pinch/Bijker? Terms are politicised and decisions over terms are politicised. The unrecognised politics that Jon performed as he translated Pinch/Bijker into familiar terms is fore-grounded.

In pursuing questions about stakeholders, we can extend the political point and investigate whether these terms carry different affordances, opportunities and consequences for organising. So, now let us return to the vignette and continue with the moments that follow from the exchange in the atrium (at least in student memory). This is when the static vignette takes on a life of its own in inquiry-based learning. At this point, students explore notions of stakeholder and find richer accounts than that originally offered by Jon. So, casualness is being challenged. In parallel, we follow their investigations and draw their attention to a particular study from the modules 'reading list': that is an STS account by Law and Callon, (1992) involving an empirical discussion of the death of TSR2 (a military aircraft).

We select this example from STS because this particular case offers a further way of thinking and doing stakes: through the metaphor of neighbours. In the context of Jon and his colleagues, the TSR2 case can be juxtaposed with their concerns over stakeholders and so allow access to a more dynamic description of relationships between others in organising. Neighbourliness is both a familiar and rich way to imagine organising relationships and, as WM points out, "you couldn't sustain a popular TV soap about stakeholders". We are now able to focus on the relationship between concepts, performances and locations of contrasting forms of organising.

Developing students to think with notions such as interpretive flexibility offers opportunities, indeed gives permission, for opening up closed and rehearsed performances. At the very least we are trying to demonstrate that:

"the actions and solutions proposed by actors (were) shaped by the way in which they articulated problems while: "action" and "practices" simultaneously structured the social process of problem definition” (de la Bruhèize, 1992:140).

The use of STS empirical work here is highly relevant. The literature is, to a certain extent, exotic. It is not overtly meaningful to the concerns of management and students are both frustrated and intrigued by the choice. Importantly, this is not a case of continuously presenting students with more complicated material from a subject area outside their experience, rather it involves a commitment to working with students in order to build connections between 'interesting things about organising from here' and 'interesting things about organising from there'. Overall, we want students to be sensitised to knowledge production processes of management and to confidently pose questions about the tools and techniques of management and imaginaries that are wielded in daily organising.

Let us now turn attention to one of the major contributions that STS theory offers management education: namely the material character of management action. In 
order to make our point here we move the action on a further week, and this time we move to a seminar room where the students are focusing their effort on the assignment problem. Now, the students are caught up in doing management and in the process they bring assumptions, techniques and tools - charts, models and characterisations to the table and we find some key concepts in the original document sidelined and new imperatives emerge:

(Scene - Seminar Two. Week Three. Students have been busy - beavering away forming groups and reading assignments. Seminars are getting rather other worldly. The assignment has somehow become a brief in student talk. Students have picked up on one word in the introduction and turned it into a key concept. But, 'the brief' is gathering power as they talk)

Michael: ... in the brief it says that we have to form (pause a beat) syndicates. er.. can we work across seminars?

WM: I guess so... I have no objection in principle, but you'll have to make it work 'cos of the timetables

Huw so, in the brief it says we are supposed to do a team building thing with the rest of the students - is that right?

WM: er - team building? Where did you get that from?...

Huw here, it says make everyone feel included

WM: $\quad$ what do the rest of you make of that?

Alice: From the Brief is seems clear to me that we are supposed to make everybody know which Faculty they are in.

Huw: .. it says department here...

Alice... what's the difference, (frustrated) - oh / don't get it

( debate continues with WM out of their loop - for some reason students exclude him from this bit of clarification... WM waits to be asked back in. Energetic work follows with diverse lines of thought to be pursued. Finally, after ten minutes or so)

Claire: (adopting summarising voice) OK. So, we can be in groups across seminars, The Brief wants us to get together and do something - so that we all get to know each other better...

(general agreement, some nodding, all seem to be thanking various gods somebody has got 'it' - everyone was getting twitchy with the going round in circles but did not know how to do STOP. Claire performs the stop)

$$
\begin{gathered}
\text { Claire ...so, / think it would be a good idea if we all exchanged mobile numbers } \\
\text { and email addresses... so'es we keep in touch }
\end{gathered}
$$

(relief all round... confusion disappears as they fix on doing this activity and pieces of paper, whiteboards and phones all enrolled.)

(The exchange of 'information' done, a timekeeper type begins to pack away. Students and lecturer move toward the door - small talk continues. As WM hangs back he overhears an exchange outside) 


$$
\begin{aligned}
& \text { Alice: (quietly to friend)... It's rubbish, I wouldn't be doing it like this - they } \\
& \text { aren't telling us anything, how can we learn anything like this, its daft } \\
& \text { (... continues out of range) }
\end{aligned}
$$

We have two observations to make at this point. Firstly, our students are involved in activities of selecting, associating, translating, defining, fixing and naming things. And, secondly, materials matter.

In using the above vignette to explain our interest in matters of translation, fixing and naming, we draw particular attention to the 'brief'. Interestingly, in the original assignment the notion of a brief is cursory and appears only as a throw away sentence of four words, "The brief is open.” However, as we listen to student talk in week three, and follow their activities, the word brief carries significant meaning - and is taking a central anchor point in their organising and sense making. Somewhere in meetings, emails and discussions, the brief is being translated from lower to upper case. We ponder on this situation with the students. Everyone wonders quite how this naming of things happened - no one it seems is quite sure.

At this point, not only has the brief' gained ground and authority in student conceptualisations of the problem, some of our original assignment concepts have been absented. For example, 'alienation, ${ }^{10}$ and 'cohesion, ${ }^{11}$ appear in the original assignment but they rapidly gave way to talk of inclusion and team building. Things are getting real and it is time for a short debrief.

In doing this debrief, our intention is to work with the students and explore how, in managing the uncertainties that are presented, we have all actively engaged in political talk and practices. In this context, we collectively examine how, in explaining their activities and ideas, students repeatedly appeal to other experiences, and other locations. For example, students draw on their previous educational experiences and connect the current task with work they have done when participating in Young Enterprise competitions. Other students connect the task with current work experiences - noting how their employers have similar problems and that they have brought in consultancies to work against a Brief. On the other hand, students taking joint honours with Marketing will simply argue that the assignment is a brief - as many of their assignments are indeed defined this way.

In week three we begin to reflect on processes of definition and fixing by focussing on both what knowledge is being brought into the mix and how it is used. Now, our STS readings are valuable. Pinch and Bijker have already opened up interpretative flexibility and demonstrated that social groups are not necessarily neatly bounded and problems are not always shared. In adding to the STS accounts we now have an ANT literature to draw on, and Latour directly enters into the proceedings. Now, we can turn attention to situations, performances and materials. Notions of material association and delegation are made meaningful to the naming and fixing that we have all observed. The making of The Brief, has direct parallels with the making of a project demonstrated by Latour in his study Aramis (1996).

Once ANT has entered into management education, we are able to focus student attention on the role of materials in the process of fixing, naming and doing. To illustrate this point, we return again to the vignette above, and focus on how Claire 'manages'. It is Claire who appears the strongest actor in controlling frustration and bringing order to uncertainty. Claire's organising is notably material as she sets about organising time, communications and people. Mobile phones and email accounts are 
turned into resources for the project and as a result, she expects everyone to make their personal contact details available to others in the group: and they do. In pursuing the moment, the whiteboard becomes a place where ideas are captured and the technologies for teaching and learning become Claire's resource for "getting things done" and "moving on". At this moment, the others act differently: writing paper emerges, whiteboard notes are copied down and a sense of order gradually emerges. The moment may appear mundane but, it is a moment that we return to regularly with the students in debriefing. The students felt the drama here and connected strongly with the relationship between their feelings, expectations and behaviours. Materials were demonstrably important in turning their frustration into order. It is in this way that the students came to know that materials matter.

Just as with our earlier example, it is worth considering now what happens once Claire has everyone busy doing 'stuff'. In practical terms a great deal begins to happen. Within a week of emails being exchanged we find all manner of materials circulating. Indeed, it seems a short step from exchange of email addresses to the formation of project plans and organisational master plans. Very quickly, the functional structures that students hang their hopes on get named and nominally resourced. Well understood models, functions and processes become elevated and design, production, marketing and so forth are invoked as unproblematic elements of a system that can deliver the goods. Alongside this we see various management diagnostic instruments being found and aired. We were particularly interested to find students enrolling psychological and cognitive profiling as they tried to fit individuals to roles in successful team building ${ }^{12}$. We had no way of knowing that students would take this particular approach to resourcing and dividing up labour but once they did, it was certainly worth reflection.

So, within two weeks of Claire 'moving things on' a great deal of work has been undertaken. In the lectures and seminars things are moving on too. Mol enters the fray and OP becomes a resource for thought and action. In the debriefing session, attention turns to how resourcing the project became a question of assessing individual cognitive and psychological style rather than, for example, a question of a cooperation, participation, community, mutuality, ownership or even curiosity. In examining the vexed nature of such optionality, we juxtapose this way of resourcing with Mol's discussion of the multiple realities of anaemia. We connect students organising practices with Mol's discussion of how detection of anaemia became fixed in place as a 'clinical' practice. The discussion revolves around Mol's claim that whatever the acknowledged reason for this 'fact' of the matter, in fixing it (that fact) in place, there is displacement of the decision as it shifts from one site to another (Mol, 1999: 80). Our point here is to examine options for organising and re-imagine what it might mean if these options were put into practice as part of the 'solution' what different experiences of work, different problems and different possibilities might be surfaced if performances shifted (even slightly) and other networks were enrolled.

\section{Conclusion}

This article has contributed to concerns over how STS can mean business by demonstrating the role of STS in management education. The intention is to extend the critical management education agenda and point to new possibilities that STS affords. The aim was to demonstrate the value of bringing STS theory, method and empirical works directly into management education. We have shown that combining 
STS sensibilities and practice with problem-based learning offers a space in which science and technology become valuable points of conversation, reflection and departure. We claim that STS and management education share a common concern for organising. We suggest that the juxtaposition of apparently unconnected materials and performances has value in that it affords opportunities to foreground obscured organising aspects of managerial practice. In our paper we show that contributions from social construction of technological systems (SCOT), actor network theory (ANT) and ontological politics (OP) bring specific affordances to the study of organising. The introduction of SCOT allowed us to examine mundane materials and explore these materials as physical expressions of political interests. Extending our concerns to ANT allowed students the opportunity to investigate management as material, durable and relational. The third STS contributor, ontological politics, demanded that attention was paid to ontological concerns. Combining these three STS voices elevated materiality, durability and multiplicity in management decision making practices. We show that our introduction of STS to management education produced uncertainty and unsettled extant relationships. We illustrate how ethnographic fieldwork sensibilities interrupted this destabilising tendency and enabled us to reframe educational relationships and outcomes in ethnographic terms: collaboration, complicity and rapport. Both students and tutors found value in uncertainty. The implications of integrating STS into management education were demonstrated in the ethnographic account and discussed in terms of both the content and delivery of management education. We concluded that a combination of STS theory, ethnographic conversational style and problem-based learning allowed students to re-imagine management and, in so doing, raise new possibilities for examining experiences of work, management problems and organising possibilities. In sharing our experiences of connecting STS to management education, we point to a possible way that STS can mean business.

\section{Notes}

We are deeply indebted to all our students who have helped us to pursue our longstanding interest in management. In particular we would like to pay special thanks to students who made Avrenim during MGT2005 in the academic year 2005/06.

1 Post-structuralist analyses of management are wide ranging and draw attention to the construction of management by reference to particular performances or absences. Concerns include aesthetics, emotionality, embodied practice, artefacts and space. (e.g. see Grey and Willmott, 2005; Linstead, Fulop and Lilley , 2004; Linstead, 2004b; Strati, 1999; Hassard and Parker, 1993; Hassard, 1993; Alvesson and Willmott, 1992)

2 For classic studies of science (e.g. see sociologists Latour and Woolgar, 1979; Collins, 1985. Historians Shapin and Schaffer, 1989; Shapin, 1996. Anthropologists Downey and Dumit, 1997. Feminists Harding, 1986; Haraway, 1991. Ethnomethodologist Lynch 1985, 1993.)

3 It is important to point out here that whilst STS is the only formal theory that we draw into MGT2005 our students are entitled to extend this content should the need they deem it necessary. Extensions are welcome but any such development must be explained and justified before we will follow where the students lead. The focus is always on theoretical extension and comparison not replacement.

4 For the academic year in question the outcomes for MGT2005 were "that on successful completion of the unit the student will be able to: critically examine the notion of rational decision making; understand the role of interpretation, boundary and transformation in decision making; consider decision making as a material 
performance; discuss the role of power in decision making processes.”

There are some notable examples where deep ethnographic fieldwork has informed STS theorising. (e.g. see Latour and Woolgar, 1979; Latour, 1987; Pinch and Trocco, 2002; Mol, 2002; Fortun, 2001; Rabinow, 1996, 1997; and Wynne, 1996.)

We draw on Clifford (1990) where he observes different moments in fieldwork: transcription is one moment. Our point here is that in collaborative ethnographies such moments often move to become opportunities for conversations with our field 'subjects' (for want of a better word). In such conversing and debating the so-called subjects are drawn into our world and come to be concerned over our crafting of theory/analysis and interpretation.

7 It is worth noting here that the social construction here was not appealing to or debating with notions of social construction derived from either Foucault or Berger and Luckmann. Instead, the emerging explanations of social construction of SCOT were drawing primarily on literature in history and philosophy of science and in most cases had its own integrity and consequently its own foci - (see e.g. sources cited by Latour and Woolgar 1979; Bloor 1991; Bijker, Hughes and Pinch (eds.) 1988)

8 We have selected moments that students referred to repeatedly as they reflected upon their coursework. These were the moments when, for many, the penny dropped or an idea was laid down.

9 We follow Dugdale (1999) in that for the purposes of confidentiality and to keep faith with our students we chose to represent fieldwork as fictional dialogues. However, in scripting these conversations we draw heavily on our field-work, fieldnotes and field-artefacts collected during 2005-06. These are not accurate verbatim reports, rather for the purpose of clarity we offer composite scenes that evoke the fieldwork and stay as close as is appropriate to the language and flow of the various meetings. In this context, characters have been drawn that cannot be mapped to any individual. In all cases, the characterizations here are selective, partial and cannot be taken as a whole and faithful representation of any individual

10 Refers to line 4 of the introduction to the assignment: “... students ... being alienated from the department"

11 Refers to line 9 of the introduction to the assignment: “...needs for 'inclusiveness' and 'cohesion'.,

12 There are a range of management instruments that are designed and regularly deployed in profiling individuals for team roles. Interestingly, both Belbin's study of team roles and Myers-Brigg personality types have been regularly drawn into student organising

\section{References}

Alvesson, M. \& Willmott H., eds (1992) Critical Management Studies. London: Sage.

Barad, K. (2003) 'Posthumanist Performativity: toward an understanding of how matter comes to matter', Signs: Journal of Women in Culture \& Society 28 (3): 801-82.

Bijker, W. E and Law J., eds (1992) Shaping Technology/Building Society. Cambridge, MA: MIT Press.

Bijker, W. E., Hughes T and Pinch, T., eds (1987) The Social Construction of Technological Systems. Cambridge, MA: MIT Press.

Bloor, D. (1991) Knowledge and Social Imagery, 2nd Edn. Chicago: University of Chicago Press.

Clifford, J. (1990) 'Notes on (Field)-notes', in R. Sanjek (ed.) Fieldnotes: the making of anthropology, pp.47-70. Ithica NY: Cornell University Press.

Clifford, J. (1997) Routes: travel and translation in the late twentieth century. Cambridge Mass.: Harvard University Press.

Collins, H. (1985) Changing Order: replication and induction in scientific practice. London: 
Sage.

de la Bruhèze, A. (1992) 'Closing the Ranks: Definition and Stabilization of Radioactive Wastes in the U.S. Atomic Energy Commission, 1945-60', in W. E. Bijker and J. Law, (eds) Shaping Technology/Building Society, pp. 140-174. Cambridge, MA: MIT Press.

Downey, G. and Dumit, J., eds Cyborgs and Citadels: anthropological interventions in emerging sciences and technologies. Santa Fe School of American Research Press. Distributed by University of Washington Press.

Dugdale, A. (1999) 'Materiality: juggling, sameness and difference', in J. Hassard and J. Law (eds) Actor Network and After, pp. 113-135. Oxford: Blackwell.

Fortun, K. (2001) Advocacy After Bhopal: environmentalism, disaster, new global orders. Chicago: University of Chicago Press.

French, R. and Grey, C., eds (1996) Rethinking Management Education. London: Sage.

Fulop, L. (2002) 'Practising What You Preach: Critical Management Studies and its Teaching' Organization 9(3): 428-436.

Grey, C. Knights, D. and Willmott, H. (1996) 'Is a Critical Pedagogy of Management Possible?' in French, R. and Grey, C., eds (1996) Rethinking Management Education, pp.94-110. London: Sage

Grey, C (2002) 'What are Business Schools For? On silence and voice in management education' Journal of Management Education 26(5): 496-511.

Haraway, D. J. (1991) Simians, Cyborgs and Women: the reinvention of nature. London: Free Association Books.

Harding, S. (1986) The Science Question in Feminism. Ithica: Cornell University Press.

Hassard, J. (1993) Sociology and Organization Theory: positivism, paradigms and postmodernity. Cambridge: Cambridge University Press

Hassard, J. and Parker, M., eds (1993) Postmodernism and Organizations. London: Sage.

Latour, B, and Woolgar, S. (1979) Laboratory Life: the construction of scientific facts $\left(2^{\text {nd }}\right.$

Edition 1086). Princeton NJ: Princeton University Press.

Latour, B. (1991) 'Technology is society made durable' in J. Law (ed.) A Sociology of Monsters: Essays on power, technology and domination. London: Routledge.

Latour, B. (1992) 'Where are the missing masses? in The Sociology of a Few Mundane Artifacts' in W. E Bijker and J. Law, (eds) Shaping Technology/Building Society, pp. 225-258. Cambridge, MA: MIT Press.

Latour, B. (1995) 'The'Pedofil of Boa Vista: A Photo-Philosophical Montage', Common Knowledge 4 (1): 144-187.

Latour, B. (1996) ARAMIS, or The Love of Technology translated by Catherine Porter. Cambridge, MA: Harvard University Press.

Law, J. (1999) 'After ANT: complexity, naming and topology', in J. Law J and J. Hassard (eds.) Actor Network Theory and After, pp. 1-14. Oxford: Blackwell.

Law, J. (2002) Aircraft Stories. Decentering the Object in Technoscience. Durham and London: Duke University Press.

Law, J. and Callon, M. (1992) 'The Life and Death of an Aircraft: a Network Analysis of Technical Change', in W. E Bijker, and J. Law (eds.) Shaping Technology/Building Society, pp. 21-52. Cambridge MA: MIT Press.

Law, J. and Hassard, J., eds (1999) Actor Network Theory and After. Oxford: Blackwell.

Linstead, S, Fulop L. and Lilley S. (2004) Management and Organization: a critical text. London: Palgrave.

Linstead, S. (2004) Organization Theory and Postmodern Thought. London: Sage.

Lynch, M. (1985) Art and Artifact in Laboratory Science: a study of shop talk and shop work in a research laboratory. London: Routledge and Keegan Paul. 
Lynch, M. (1993) Scientific Practice and Ordinary Action. Ethnomethodology and Social Studies of Science. Cambridge: Cambridge University Press.

Marcus, G. (1997) 'The Uses of Complicity in the Changing Mise-En-Scene of Anthropological Fieldwork', Representation 59: 85-107.

Mol, A. (1999) 'Ontological politics: A word and some questions', in J. Law. and J. Hassard (eds.) Actor Network Theory and After, pp. 74-89. Oxford: Blackwell.

Mol, A. (2002) The Body Multiple: ontology in medical practice. Durham and London: Duke University Press.

Mol, A. and Law, J. (1994) 'Regions, Networks and Fluids. Anaemia and Social Topology', Social Studies of Science, 24: 641-671.

Mutch, A. (2002) 'Actors and Networks or Agents and Structures: towards a realist view of information systems', Organization 9 (3): 477-496.

Oudshoorn, N. and Pinch, T. (2003) How Users Matter: The Co-construction of Users and Technology. Cambridge, MA: MIT Press.

Parker, M. (2002) Against Management: organization in the Age of Managerialism. Cambridge: Polity.

Pinch, T. and Bijker, W. E. (1987) 'Social Construction of Facts and Artifacts: or how the sociology of science and the sociology of technology might benefit each other', in W. Bijker, T. Hughes, and T. Pinch (eds.) The Social Construction of Technological Systems, pp. 17-50. Cambridge MA: MIT Press.

Pinch, T. and Trocco, F. (2002) Analog Days: the invention and impact of the Moog synthesizer. Cambridge MA: Harvard University Press

Rabinow, P. (1996) Making PCR: a story of biotechnology. Chicago: Chicago University Press.

Rabinow, P. (1997) 'Science as a Practice: The Higher Indifference and Mediated Curiosity', in G. L. Downey, and J. Dummit (eds.) Cyborgs and Citadels: Anthropological Interventions in Emerging Sciences and Technologies, pp. 193-208. Santa Fe School of American Research Press. Distributed by University of Washington Press .

Roberts, J. (1996) 'Management Education and the Limits of Technical Rationality: the conditions and consequences of management practice', in R. French, and C. Grey (eds.) Rethinking Management Education, pp. 54-75. London: Sage.

Shapin, S. (1996) The Scientific Revolution. Chicago: University of Chicago Press.

Shapin, S. and Schaffer, S. (1989) Leviathan and the Air-Pump: Hobbes, Boyle and the experimental life. Princeton: Princeton University Press.

Strathern, M. ed (1995) Shifting Contexts. Transformations in Anthropological Knowledge. ASA Decennial Conference Series: The Uses of Knowledge: Global and Local Relations. London: Routledge.

Strati, A. (1999) Organization and Aesthetics. London:Sage.

Wynne, B. (1996) 'May the sheep safely graze? A reflexive view of the expert-lay divide', in S, Lash, S, Brinislaw and B, Wynne (eds.) Risk, Environment and Modernity: towards a new ecology, pp. 44-83. London: Sage

Zald, M. N. (2002) 'Spinning Disciplines: Critical Management Studies in the Context of the Transformation of Management Education’ Organization 9(3): 365-385. 